\title{
The emotional wellbeing of New Zealand midwives: Comparing responses for midwives in caseloading and shift work settings
}

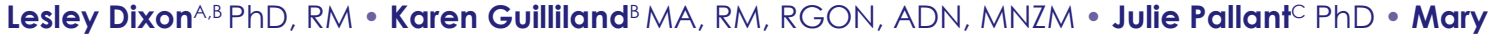 \\ Sidebotham ${ }^{D}$ PhD, RM • Jennifer Fenwick ${ }^{E}$ PhD, RM • Judith McAra-Couper PhD, RM, RGON • \\ Andrea Gilkison ${ }^{F}$ PhD, MEd, RM
}

${ }^{\text {A Corresponding }}$ Author:practice@ nzcom.org.nz

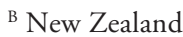
College of Midwives

\section{Department} of Rural Health,

University of Melbourne, VIC, Australia

${ }^{D}$ School of Nursing and Midwifery, Griffith University, QLD, Australia

${ }^{\mathrm{E}}$ Gold Coast University Hospital; and Centre for Health Practice Innovation, Griffith Health Institute, Griffith University, QLD, Australia

\section{${ }^{\mathrm{F}}$ Midwifery} Department, Auckland University of Technology

\begin{abstract}
Background: Ensuring the psychological wellbeing of midwives is becoming increasingly recognised as an important strategy in maintaining a healthy workforce and retaining midwives within the profession. Midwives in New Zealand can choose to be self-employed and work in the community, providing continuity of care to a caseload of women (self-employed caseloading), or can be employed to work within a maternity hospital environment (generally shift work). Some choose to work in both work settings (self-employed and employed by an organisation).
\end{abstract}

Aim: The overall aim of this study was to explore the emotional wellbeing of midwives in New Zealand. The first objective was to describe and compare the demographic and work-related factors of midwives who were (a) self-employed, (b) employed by an organisation or (c) both self-employed and employed. The second objective was to explore factors associated with burnout within each of the three groups.

Method: Practising New Zealand midwives who were members of the New Zealand College of Midwives were invited to complete an online survey. The study package included demographic questions, the Depression, Anxiety and Stress Scale (DASS-21), the Copenhagen Burnout Inventory (CBI), Perceptions of Empowerment in Midwifery Scale (PEMS) and the Practice Environment Scale (PES).

Findings: A total of 1073 midwives responded with 44\% ( $=473)$ self-employed, $42 \%(n=452)$ employed and 14\% ( $n=148)$ both self-employed and employed. Employed midwives worked fewer hours (median 32hrs) than the other two groups (median $40 \mathrm{hrs}$ and $36 \mathrm{hrs}$ respectively) but had significantly higher levels of work and personal-related burnout as well as anxiety. Employed midwives also reported lower levels of autonomy, empowerment and professional recognition. Aspects of the work environment found to be associated with burnout (particularly for employed midwives) were inadequacy of resources, lack of management support, and lack of professional recognition and development opportunities.

Conclusion: While levels of stress and depression were high for all midwives, self-employed midwives providing continuity of care to a caseload of women had better emotional health and less burnout than midwives working in an exclusively employed capacity.

Keywords: burnout, anxiety, continuity of care, employment, self-employment, caseload model

\section{INTRODUCTION}

Ensuring the emotional wellbeing of individual midwives is recognised as an important strategy in retaining midwives within the profession and maintaining a healthy midwifery workforce (Ball, Curtis, \& Kirkham, 2002; Deery, 2005; Kirkham, Morgan, \& Davies, 2006). Contemporary working conditions can often place increased demands on midwives when efficiency, cost effectiveness and administrative requirements are prioritised over relationships and women's care provision. Factors such as a stressful work environment (Hildingsson, Westlund, \& Wiklund, 2013) and insufficient staff and resources have been found to negatively influence job satisfaction and emotional wellbeing (Ball et al., 2002). On the other hand, occupational autonomy, social support and the ability to develop meaningful relationships with women have been found to sustain midwives and potentially protect against burnout (Collins, Fereday, Pincombe, Oster, \& Turnbull, 2010; Kirkham et al., 2006; Sandall, 1997; Yoshida \& Sandall, 2013).

Occupational burnout is characterised as a state of emotional, physical and mental exhaustion and is considered to be an adaptive response to high levels of stress (Seidler et al., 2014). Service-related professions (such as teachers, nurses and doctors) have been found to have a high prevalence of burnout although there is little agreement on how burnout is defined (Bakker, Schaufeli, Sixma, Bosveld, \& van Dierendonck, 2000; Borritz et al., 2006; Roberts, Cannon, Wellik, Wu, \& Budavari, 2013). In the United Kingdom (UK) studies that have explored burnout in midwives (Sandall, 1997, 1998) and reasons for leaving the profession (Ball et al., 2002) have found a range of issues related to the working conditions within the National Health Service. 
Insufficient resources, lack of management support, not having control over work and not having the time to develop or sustain relationships with women or colleagues were cited as reasons for leaving midwifery.

More recently Yoshida and Sandall (2013) explored and compared work factors related to burnout in 238 UK midwives from one Hospital Trust, who worked either in the community or hospital setting. The study found that, while longer working hours were associated with burnout, high levels of occupational autonomy were protective against burnout. Midwives who worked in the community and those who worked in the hospital had different contributing factors for burnout. Community midwives had higher levels of team work, more satisfaction and autonomy but also higher levels of stress.

Consistent with the system in the UK, midwives in New Zealand can work either in a hospital or a community setting or a combination of both. When working within the community setting, however, the majority of midwives are self-employed and contract directly with the Ministry of Health to provide maternity services to women under the Maternity Services (Section 88) notice (Ministry of Health, 2007). In this situation the midwife works as a Lead Maternity Carer (LMC). LMCs provide continuity of midwifery care to a defined number of childbearing women every year, commonly referred to as a caseload. They work across the full scope of midwifery practice providing primary care during pregnancy, labour and birth and the early transition to parenthood (six weeks postpartum). Similarly, midwives who work within maternity facilities (tertiary/secondary hospitals or primary birthing units) work across their scope but are employed to provide midwifery care for women who are admitted to the facility as part of the maternity team providing care for women with complex issues. A small proportion of midwives (3.5\%) are employed by a maternity facility to provide care to a caseload of women (Midwifery Council of New Zealand, 2013). New Zealand midwives often move between employed and self-employed work, depending on personal and family needs and general life circumstances (Midwifery Council of New Zealand, 2013). Some midwives work in both settings, providing LMC care to a small caseload of women whilst working a few shifts at a local maternity facility. Those working as self-employed LMC midwives enjoy a high degree of occupational autonomy in determining their caseload, work hours and care provision. For midwives working within maternity hospitals, the requirements of the facilities and organisational factors can influence their levels of autonomy, work hours and care provision.

The sustainability of working as a LMC midwife has been called into question because of the often extensive "on call" requirements and potential for long working hours. A telephone survey of 94 midwives who worked as LMCs in one region of New Zealand found that the need to work long hours, to be on call 24/7 and a lack of time for family and friends led to exhaustion and were reasons for leaving caseloading practice (Wakelin \& Skinner, 2007). Conversely, providing continuity of care and the quality of the relationships with women supported and sustained these midwives (Wakelin \& Skinner, 2007). Matthews, Scott, Gallagher, and Corbally (2006) explored the experiences of 12 LMC midwives who experienced burnout, finding that burnout was often masked and little understood. Young (2011) argued that being so readily available to women and the unpredictable nature of caseload work had the potential to increase the level of occupational burnout. Building on this work, New Zealand researchers Donald, Smythe, and McAra-Couper (2014) used action research to explore "ways of working" that ensured a positive work-life balance for 16 caseloading midwives. These midwives had identified a tension between their work and home commitments, and a potential risk of burnout. The midwives enjoyed the positive aspects of providing continuity of care but struggled to ensure structured time off. The authors developed a "work-life balance tool" designed for midwives to identify whether they needed to make changes to support their own work-life balance. They argued that there is a need to create and support an optimal wellbeing culture within the midwifery profession.

Similarly, McAra-Couper et al. (2014) interviewed 11 caseloading midwives who had been in practice for more than eight years to determine what sustained and supported them to continue to work as LMCs. The study found that working in partnership with women, and having supportive working relationships with midwives who had a shared philosophy, were important when managing the unpredictability of being on-call. Although McAraCouper and associates identified a need for midwives to negotiate boundaries with women, ultimately it was the "joy" of working closely with women across the entire childbirth episode that sustained midwives and supported their continued commitment to working in a caseload model.

Although there is a growing body of research examining the experience of midwives working in different models of care, no studies specifically explore the emotional wellbeing of midwives in New Zealand, where continuity of care is an expectation within the national health maternity service. The emotional wellbeing of midwives needs exploring, and specifically what factors may decrease or protect the emotional wellbeing of midwives (wherever they work) within the New Zealand context of maternity care.

This study is now situated within a large international programme of work referred to as WHELM (Work, Health \& Emotional Lives of Midwives) which is designed to explore the relationship between the emotional wellbeing of midwives and the work environment across a number of different maternity care contexts (Sweden, Australia and New Zealand). In this paper we describe and compare the demographic and work-related factors of New Zealand midwives who were either (a) self-employed or (b) employed by an organisation or (c) both self-employed and employed. The second objective was to explore factors associated with burnout within each of the three groups.

\section{METHOD}

A quantitative cross-sectional design and survey methodology was used. Ethics approval was provided by AUTEC (Auckland University of Technology Ethics Committee) (13/211 Exploring the emotional wellbeing of midwives in New Zealand).

\section{Setting}

In 2013 the New Zealand Midwifery Council reported that there were 2,938 midwives with a practising certificate working in New Zealand (Midwifery Council of New Zealand, 2013). As previously described, midwives in New Zealand work in a variety of ways (self-employed/ employed/both), as well as across different work settings and regions of New Zealand (metropolitan, rural and remote).

\section{Participants}

In September 2013 all actively practising midwife members of the New Zealand College of Midwives, who had a valid email address and had agreed to receive non-practice-related emails, were invited to participate $(\mathrm{n}=2236 ; 76 \%$ of the total number of practising midwives in New Zealand). 


\section{Recruitment and Data Collection}

Midwives were invited via email to participate. The email included a letter of invitation outlining the aims and objectives of the study and the contact details of the New Zealand project manager, should clarification be required. Within the email was a live link to the questionnaire platform which hosted the survey (Qualtrics). Consent was implied through completion of the survey.

The study adhered to the ethical principles set down by AUTEC. Anonymity of participants was assured as no name or identifying data were collected. Completed surveys were given numerical identifiers to enable participant responses to be tracked according to anonymised demographic data. Given the nature of the study, potential participants were also provided with the contact details of the Midwifery Advisor to the New Zealand College of Midwives, should completing the study generate emotional distress and/or participants request additional support or advice. Counselling resources were made available.

\section{Instruments}

The survey consisted of a demographic section that included personal information (i.e., age, marital status, level of education), as well as work-related variables, such as model of care and hours worked per week. The subsequent sections contained a number of validated measures.

\section{The Depression, Anxiety and Stress Scale (DASS-21)}

The DASS-21 is a three domain scale that measures depression, anxiety and stress (Lovibond \& Lovibond, 1995). Each subscale has seven items, with participants being asked to consider how much the statement applied to them over the past week $(1=$ did not apply to $4=$ most of the time). Examples of items in the depression subscale included "I felt down-hearted and blue" and "I felt I wasn't worth much as a person". "I was aware of dryness of my mouth" is one item from the anxiety subscale and "I found myself getting agitated" is an example from the stress subscale. Higher scores indicate higher levels of depression, anxiety and stress. Guidelines are provided by the scale authors to classify scores into a number of clinical categories (normal, mild, moderate, severe, extremely severe) (Lovibond \& Lovibond, 1995). Norms are also available for each of the three scales and the values reported in the scale manual for female respondents were used in this study for comparison.

The DASS-21 has been used extensively within the international context. As such, the psychometric properties of the three domains (i.e., validity and reliability) have been well tested (Henry \& Crawford, 2005). In the current study the Cronbach alpha coefficient for each subscale, which is a measure of reliability or internal consistency, was found to be .84 for stress, .72 for anxiety, and .88 for depression. As values exceeded the recommended level of .70 this suggests the scale was reliable in this context (Nunnally, 1978).

\section{The Copenhagen Burnout Inventory ( $\mathrm{CBI}$ )}

The CBI is a three domain scale that measures the sources of burnout that individuals perceive they are experiencing (Deery \& Kirkham, 2006; Kristensen, Borritz, Villadsen, \& Christensen, 2005). The first subscale is related to personal burnout and consists of six items such as, "How often do you feel tired?" The second subscale uses seven items to capture work-related burnout. Two examples from this domain are: "Does your work frustrate you?" and "Are you exhausted in the morning at the thought of another day at work?" The third domain relates to client burnout and consists of six items. An example of an item from this subscale is: "Do you find it hard to work with women?" There is a mix of response formats, with some items assessing frequency (never/ almost never to always) and others measuring intensity (very low degree to very high degree). All items use a five-point scale with scores being adjusted so that the possible score range for all three subscales range from 0 (low burnout) to 100 (high burnout). The Cronbach alpha values were high for all subscales (personal burnout alpha=.90, work-related burnout alpha $=.87$, clientrelated burnout alpha=.88), supporting their reliability.

\section{The Perceptions of Empowerment in Midwifery Scale (PEMS)}

The PEMS was developed by Matthews, Scott, and Gallagher (2009) to measure midwives' perceptions of conditions which could be considered to be important to empowerment. The scale has 22 items, with responses ranging from strongly disagree to strongly agree. In the original scale there were three subscales: (a) Autonomous Practice, (b) Effective Management and (c) Womencentred practice. However, factor analysis undertaken for our cohort suggested an alternative four-domain structure representing Empowerment (four items - "I have autonomy in my practice"), Supportive Manager (five items - "I am valued by the manager"), Professional Recognition (five items - "I am recognised as a professional by the medical profession"), and Skills and Resources (five items - "I have adequate access to resources for birthing women in my care") (Pallant, Dixon, Sidebotham, \& Fenwick, 2015). Total scores for each of these subscales were calculated by adding scores from each item and dividing by the number of items. Higher scores equate to higher levels of empowerment.

\section{The Practice Environment Scale (PES)}

The PES is a 31-item scale designed to measure the organisational characteristics of a nurse's work setting that facilitate or constrain professional practice (Kirkham \& Morgan, 2006). The PES was adapted for use in this study by changing the word "nurse" to "midwife". One item was removed from the scale (Use of nursing diagnoses) as it was considered inappropriate in the context of midwifery practice. In the original scale there were five domains, with participants being asked to respond using a five-point Likert scale where one equalled "strongly disagree" and five was "strongly agree".

Although the scale has been widely used in the nursing context, there has been very little research using the PES in a midwiferyspecific context. Exploratory factor analysis of the revised items revealed a four-factor structure: Quality of Management (six items - "A Midwifery Unit Manager who is a good manager and leader"), Midwife-Doctor Relations (three items - "Doctors and midwives have good working relations"), Resource Adequacy (four items - "Enough staff to get the work done"), and Opportunities for Development (seven items - "Opportunity for midwives to participate in policy decisions"). Totals for each of these subscales were calculated by adding scores from each of the individual items and dividing by the number of items. The higher the score the more satisfied midwives were with their practice environment.

As self-employed midwives routinely work in the community and home environment, coming in and out of the hospital environment based on their clients' needs, they were asked to complete the PES from the perspective of the maternity hospital which their clients most frequently accessed for intrapartum care provision.

\section{Statistical Analyses}

The sample was divided into three groups based on midwives' selfreport of their employment situation (self-employed, employed, 
or both self-employed and employed). The demographic and work-related factors were compared across these three groups using Chi Square tests (categorical variables) and Kruskall-Wallis tests (continuous variables). To compare wellbeing across the groups, a series of analysis of variance tests (ANOVA) were performed. Where there was violation of the assumption of equality of variances (Levene's test), the Welsh's F test provided by SPSS as a robust test of equality of means, was used (McLardy, 2003). To identify factors associated with burnout within each of the three groups, Pearson correlation coefficients were calculated between scores on the CBI: Work Burnout scale and the PES and PEMS subscales and a number of demographic and work-related variables.

\section{Participant Characteristics}

Of the 2236 midwives sent an invitation, 1073 completed the survey ( $48 \%$ response rate). A separate question asked the midwives to identify if they were self-employed, employed, or both self-employed and employed, and this question was used for group comparisons (Table 1). Midwives who were self-employed were considered to be providing continuity of care within a caseload model. The midwives ranged in age from 21 to 70 years, the majority had children and were married or living in a de facto relationship. Table 1 shows the demographic characteristics of self-employed midwives $(\mathrm{n}=473,44 \%)$, midwives employed by an organisation $(n=452,42 \%)$ and those who were both selfemployed and employed by an organisation $(n=148,14 \%)$.

\section{RESULTS}

A comparison of work settings with the Midwifery Council workforce data is provided in Table 2 and demonstrates similar proportions of employed midwives ( $41.1 \%$ versus $49 \%)$ and employed case loading midwives (3.4\% versus $3.5 \%$ ) completed the survey. However, a larger proportion of self-employed midwives completed the survey (43.6\%) compared to the national average (32.8\%) (Midwifery Council of New Zealand, 2013).

The length of time participants had worked as a midwife ranged from 0 to 42 years with a median $(\mathrm{Md})$ for each group of between 11 and 13 years. Almost $75 \%$ of employed midwives were located in urban areas, while self-employed midwives were spread across both urban and rural areas $(\mathrm{p}<.001)$. There were significantly fewer self-employed midwives undertaking additional study $(\mathrm{n}=27$, $5.7 \%, \mathrm{p}<.001)$ compared to those who were employed $(\mathrm{n}=62$, $13.7 \%)$ or worked both as self-employed and for an organisation $(n=23,15.8 \%)$. The majority of midwives considered that they had flexibility to have time off when they needed it, and this did not differ significantly between work settings.

Self-employed midwives recorded the highest number of hours worked per week $(\mathrm{Md}=40)$, with the employed group reporting the lowest $(\mathrm{Md}=32, \mathrm{p}<.001)$. The majority of self-employed midwives worked between 29 and 40 hours (47.8\%), with a further 143 (36.2\%) working between 41 to 60 hours (Figure 1).

Table 1. Characteristics of midwives who were self-employed, employed, or both self-employed and employed

\begin{tabular}{|c|c|c|c|}
\hline $\begin{array}{r}\text { Self-employed } \\
n=473(44 \%)\end{array}$ & $\begin{array}{r}\text { Employed } \\
n=452(42 \%)\end{array}$ & $\begin{array}{r}\text { Both self-employed \& } \\
\text { employed } n=148(13.6 \%)\end{array}$ & Statistical comparison* \\
\hline
\end{tabular}

\section{Demographic factors}

\begin{tabular}{|c|c|c|c|c|}
\hline Age (Md, range) & $M d=48$ (22 to 70$)$ & $M d=47$ (21 to 70$)$ & $M d=48$ (24 to 69) & Chi Sq $=2.5, p=0.27$ \\
\hline Ethnicity (n, \%) & & & & Chi $S q=13.5, p=0.09$ \\
\hline New Zealand European & $357(75.54 \%)$ & $323(71.6 \%)$ & 115 (78.8\%) & \\
\hline Māori & $21(4.4 \%)$ & $25(5.5 \%)$ & $5(3.4 \%)$ & \\
\hline Pasifika & $6(1.3 \%)$ & $2(0.4 \%)$ & $0(0 \%)$ & \\
\hline Asian & $9(1.9 \%)$ & $3(0.7 \%)$ & $0(0 \%)$ & \\
\hline Other & $80(16.9 \%)$ & $98(21.7 \%)$ & $26(17.8 \%)$ & \\
\hline Marital status ( $n, \%$ ) & & & & Chi Sq $=1.72, p=0.42$ \\
\hline Married/de facto & $187(75.5 \%)$ & 177 (70.7\%) & $60(72.3 \%)$ & \\
\hline Single/Sep/Div/Wid & $60(24.3 \%)$ & $74(29.5 \%)$ & $23(27.7 \%)$ & \\
\hline Children ( $n, \%$ yes) & $423(89.4 \%)$ & $353(78.3 \%)$ & $127(87.0 \%)$ & Chi Sq=22.68, $p<.001$ \\
\hline $\begin{array}{l}\text { Children living at home } \\
\text { ( } n, \% \text { yes) }\end{array}$ & $296(70.5 \%)$ & $243(69.2 \%)$ & $85(66.9 \%)$ & Chi Sq=0.597, $p=0.74$ \\
\hline Caring for others ( $n, \%$ yes) & $84(17.8 \%)$ & $74(16.4 \%)$ & $39(26.4 \%)$ & Chi Sq $=7.612, p=0.22$ \\
\hline \multicolumn{5}{|l|}{ Work-related factors } \\
\hline Initial registration ( $n, \%)$ & & & & Chi Sq $=2.591, p=0.27$ \\
\hline Midwife & $265(56.0 \%)$ & $235(52.1 \%)$ & $72(49.3 \%)$ & \\
\hline Nurse & $208(44.0 \%)$ & $216(47.9 \%)$ & $74(50.7 \%)$ & \\
\hline $\begin{array}{l}\text { Length time as midwife (Md, } \\
\text { range) }\end{array}$ & $M d=11$ yrs (0 to 42yrs) & $\mathrm{Md}=13 \mathrm{yrs}$ ( 0 to $42 \mathrm{yrs}$ ) & $M d=13 y r s$ (0 to 40yrs) & Chi Sq $=1.71, p=0.42$ \\
\hline Location (n, \%) & & & & Chi Sq $=166.056, p<.001$ \\
\hline Urban & $154(34.4 \%)$ & $329(74.9 \%)$ & $51(36.4 \%)$ & \\
\hline Rural & $96(21.4 \%)$ & $48(10.9 \%)$ & $35(25.0 \%)$ & \\
\hline Both & $198(44.2 \%)$ & $62(14.1 \%)$ & $54(38.6 \%)$ & \\
\hline Work hours (Md, range) & $M d=40(0$ to 90$)$ & $M d=32(0$ to 64$)$ & $M d=36(0$ to 104$)$ & Chi Sq $=133.962, p<.001$ \\
\hline Additional study ( $n, \%$ yes) & $27(5.7 \%)$ & $62(13.7 \%)$ & $23(15.8 \%)$ & Chi Sq=20.961, p<.001 \\
\hline Flexible time off ( $n, \%$ yes) & $308(70.0 \%)$ & $291(67.2 \%)$ & 101 (74.3\%) & Chi Sq $=2.571, p=0.27$ \\
\hline
\end{tabular}

* Chi Square tests were used to compare categorical variables across groups, while Kruskal Wallis tests were used to compare continuous scores. Significant tests are shown in bold font. 


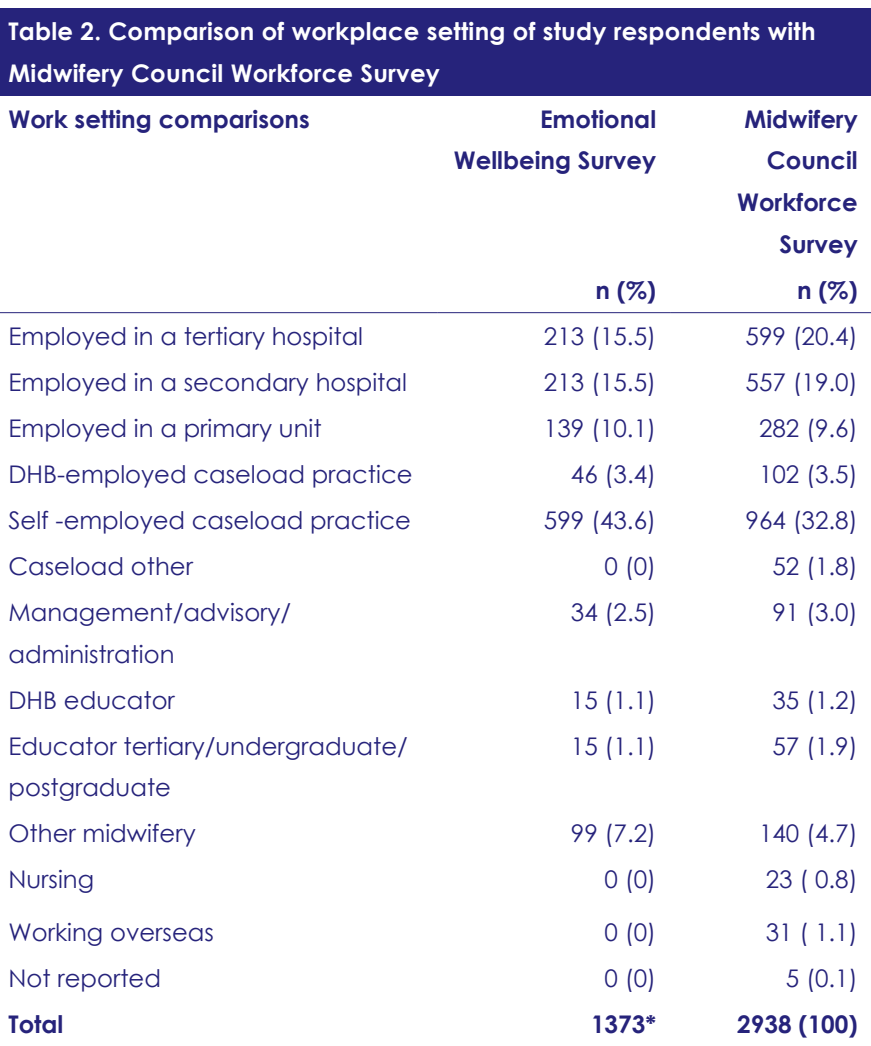

${ }^{*}$ Includes more than one response

Whereas the majority of employed midwives ( $\mathrm{n}=265,58.6 \%)$ worked between 29 and 40 hours, a further 161 (35.6\%) worked 28 hours or less and $4.9 \%$ worked between 41 and 60 hours. Midwives working in both models worked on average 36 hours, with the majority working 28 hours or less $(\mathrm{n}=51,34.5 \%)$ and a further $29.4 \%(n=44)$ working between 29 and 40 hours. These midwives were also more likely to be studying $(\mathrm{n}=23,15.8 \%)$.

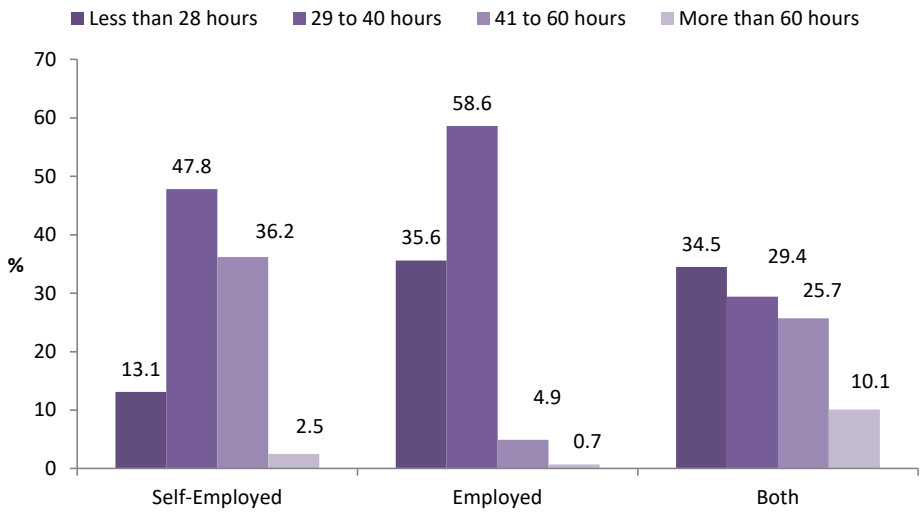

Figure 1. Work hours in average week per work setting of midwife

\section{Midwives' emotional health}

Scores on the four validated scales (DASS-21, CBI, PEMS, PES) were compared across the three employment groups (see Table 3).

\section{Depression, anxiety and stress}

On the DASS-21 the employed group recorded higher mean scores than the other two groups; however, the difference only reached statistical significance for the DASS: Anxiety scale $(\mathrm{p}=.001)$. The mean scores for the employed group were above the normative values reported in the DASS manual for both the DASS: Depression (6.52 compared to the norm of 6.14), and the DASS: Anxiety (5.27 compared to the norm of 4.8).

The proportion of the sample that fell within the clinical categories of moderate/severe/extreme on the DASS scales are presented in Table 3. On the DASS: Anxiety scale there was a significantly higher proportion $(\mathrm{p}=.04)$ of employed midwives classified in these clinical categories $(18.9 \%)$ than self-employed $(13.3 \%)$ or both employed and self-employed (12\%). There was no difference between groups for the DASS: Depression or DASS: Stress scales.

\section{Burnout}

There were significant differences among the groups on two of the three scales of the CBI. On the CBI: Work Burnout scale the employed group recorded significantly higher scores than the other two groups $(\mathrm{p}=.007)$. A similar pattern was also evident for the CBI: Personal Burnout scale $(\mathrm{p}=.03)$. For the CBI: Clientrelated Burnout scale scores were low across all three groups with the highest scores recorded in the self-employed group, although this did not reach statistical significance $(\mathrm{p}=.08)$.

\section{Work environment}

Groups were also compared for their scores on the PES, and the PEMS, with significant differences detected for five of the eight scales. The self-employed group recorded lower scores on both the PES: Doctor/Midwife Relationships subscale ( $\mathrm{p}=.004)$ and the PES: Management Quality subscale $(\mathrm{p}=.02)$. On the PEMS the employed group recorded lower scores on the PEMS: Skills and Resources subscale ( $\mathrm{p}=.001)$, the PEMS: Professional Recognition subscale $(\mathrm{p}=.004)$ and the PEMS: Autonomy and Empowerment subscale $(\mathrm{p}<.001)$. The self-employed group recorded higher scores than the other two groups on the PEMS: Autonomy and Empowerment subscale $(\mathrm{p}<.001)$.

\section{Factors associated with work-related burnout}

To identify factors associated with work-related burnout, we calculated the Pearson correlation coefficients between the CBI: Work Burnout scores and age, time worked as a midwife and hours worked per week, and scores on the PES and PEM (see Table 4). The correlation between burnout and age, years worked as a midwife, and hours worked per week were all very weak, with correlation coefficients below 0.3 . This suggests that these factors were not associated with burnout for any of the groups. For the PES the aspects of the work environment most associated with burnout were Resource Adequacy, Development Opportunities, and Management Quality. This was particularly the case for the employed midwives with correlation coefficients above .35 for each of these PES subscales.

On the PEMS, the subscales Management Support, Professional Recognition, and Skills and Resources showed the highest association with burnout. Once again correlation coefficients were higher for the employed group, suggesting that these aspects played a more important role in determining levels of burnout for this group. The correlations recorded for the group of midwives who were both self-employed and employed were lower across all measures, suggesting that the aspects measured by the PES and PEMS have less impact on their level of burnout. 
Table 3. Comparison of scores on the DASS-21, CBI, PES, PEMS for midwives who were self-employed, employed, or both employed and self-employed

\section{Self- employed Employed Both employed \& \\ $n=473(44 \%) \quad n=452(42 \%) \quad$ self- employed \\ Statistical comparison* Post hoc tests}

\section{DASS-21}

Depression (Normative sample

Mean=6.14 SD=6.92)

Anxiety (Normative sample

Mean $=4.80 S D=5.03$ )

Stress (Normative sample

Mean=10.29 SD=8.16

DASS Classifications

Depression ( $n$, \% in moderate)

severe/extreme categories)

Anxiety ( $n$, \% in moderate/severe)

extreme categories)

Stress ( $n$, \% in moderate/severe)

extreme categories)

\section{Copenhagen Burnout Inventory}

Personal

Work

Client

\section{Practice Environment Scale}

Doctor/midwife relationships

Resource adequacy

Development opportunities

Management quality

\section{Perceptions of Empowerment in} Midwifery Scale

Skills and resources

Autonomy and empowerment

Management support

Professional recognition

Mean (SD)

$5.65(7.38)$

Mean (SD)

$n=148(14 \%)$

Mean (SD)

$5.40(6.72)$

$3.84(4.42)$

$3.96(5.07) \quad 5.27(6.09)$

$10.10(8.04)$

$8.59(7.54)$

n (\%)

$15(12.0 \%)$

$58(14.3 \%) \quad 56(13.8 \%)$

$54(13.3 \%) \quad 77(18.9 \%)$

$15(12.0 \%)$

Chi $s q=6.33, d f=2, p=.04$

Employed significantly higher than the other two groups

$58(14.3 \%) \quad 56(13.8 \%) \quad 15(12.0 \%) \quad$ Chi $s q=.41, d f=2, p=.82$

Mean (SD) Mean (SD) Mean (SD)

$52.49(16.71) \quad 53.93(18.42) \quad 49.17(16.63)$

$39.67(18.21) \quad 42.81(19.82) \quad 37.69(16.49)$

$23.85(20.30)$

$22.93(19.87)$

$20.0(15.72)$

Mean (SD)

$2.43(.58) \quad 2.54(.66)$

Mean (SD) Mean (SD)

Mean (SD)

$4.25(.54) \quad 4.11(.56)$

$4.51(.49) \quad 3.88(.67)$

$\begin{array}{ll}3.40(.85) & 3.45(.97) \\ 3.97(.67) & 3.82(.65)\end{array}$

$2.90(.53)$

$2.45(.62)$

$2.82(.53)$

$2.59(.72)$

$4.28(.51)$

$4.34(.54)$

$F(2,357.5)=3.74, p=.03$

mployed significantly different to Both

$\mathbf{F}(\mathbf{2}, \mathbf{3 6 7 . 3})=\mathbf{5 . 0 0}, \mathbf{p}=\mathbf{. 0 0 7}$ Employed significantly different to Both and Selfemployed

$F(2,384.8)=2.52, p=.08$

$\mathbf{F}(\mathbf{2}, \mathbf{8 6 7})=\mathbf{5 . 5 5}, \mathbf{p}=\mathbf{. 0 0 4}$ Employed significantly different to Self-employed

$F(2,331.8)=1.69, p=.19$

$F(2,823)=2.32, p=.10$

$\mathbf{F}(\mathbf{2}, \mathbf{3 1 7 . 8})=4.17, \mathrm{p}=.02$ Self-employed significantly different to Both

$\mathbf{F}(\mathbf{2}, \mathbf{9 0 4})=\mathbf{8 . 6 2}, \mathbf{p}<.001$ Employed significantly different to Self-employed and Both

$\mathbf{F}(2,341.4)=113.4, p<.001 \quad$ Significant difference between each pair of groups

$3.58(.97) \quad F(2,335.2)=1.87, p=.16$

$3.98(.67) \quad \mathbf{F}(\mathbf{2}, \mathbf{9 0 1})=\mathbf{5 . 5 5}, \mathbf{p}=.004$ Employed significantly different to Self-employed

\footnotetext{
* Significant tests are shown in bold font.
} 


\begin{tabular}{|c|c|c|c|}
\hline & $\begin{array}{c}\text { Self-employed } \\
(n=473,44 \%)\end{array}$ & $\begin{array}{c}\text { Employed } \\
(n=452,42 \%)\end{array}$ & $\begin{array}{c}\text { Both employed and self- } \\
\text { employed } \\
(n=148,14 \%)\end{array}$ \\
\hline Correlations with Burnout scores & r & r & $r$ \\
\hline Age & $-.15^{*}$ & $-.21^{*}$ & -.14 \\
\hline Years as midwife & $-.16^{*}$ & $-.21^{*}$ & -.17 \\
\hline Hours worked per week & .06 & $.14^{*}$ & $.22^{*}$ \\
\hline \multicolumn{4}{|l|}{ Practice Environment Scale } \\
\hline Doctor/midwife relationships & $-.28^{*}$ & $-.25^{*}$ & $-.18^{*}$ \\
\hline Resource adequacy & $-.36^{*}$ & $-.46^{*}$ & $-.34^{*}$ \\
\hline Development opportunities & $-.32 *$ & $-.35^{*}$ & $-.27^{*}$ \\
\hline Management quality & $-.31^{*}$ & $-.45^{*}$ & -.17 \\
\hline Skills and resources & $-.24^{*}$ & $-.33^{*}$ & $-.20 *$ \\
\hline Autonomy and empowerment & $-.18^{*}$ & $-.25^{*}$ & -.08 \\
\hline Management support & $-.36^{*}$ & $-.43^{*}$ & $-.24^{*}$ \\
\hline Professional recognition & $-.37^{*}$ & $-.35^{*}$ & $-.22 *$ \\
\hline
\end{tabular}

${ }^{*} \mathrm{p}<.05$. Values shown in the table are Pearson Correlation Coefficients. Values less than .3 are considered small, values between .3 and .49 are considered medium, and

values are above .5 are considered large (Cohen, 1988).

\section{DISCUSSION}

The context of maternity care in New Zealand provides a unique opportunity to examine the emotional wellbeing of midwives working in different ways and work settings. The results from this study represent the views of over a third of the midwifery workforce in New Zealand. Similar proportions of the midwives in this study worked in a self-employed capacity providing continuity of care to a defined number (caseload) of women (44\%), as those in an employed model (42\%) who were more likely to be working in defined areas of practice (i.e., antenatal, intrapartum, postnatal). A smaller proportion worked across both service models. All three groups were similar in age, marital status, initial registration and length of time working as a midwife. Significantly more of the employed midwives lived in an urban area; this may be related to secondary and tertiary facilities being situated within cities or provincial towns in New Zealand. Of note is the finding that midwives working in an employed model recorded the least number of working hours of the three defined groups, yet they had significantly higher levels of personal and work-related burnout as well as anxiety. This finding is contrary to that of Yoshida and Sandall (2013), who found an association between higher levels of burnout with increased number of hours worked. Employed midwives also reported lower levels of autonomy, empowerment, professional recognition and access to resources. Aspects of the work environment associated with burnout were adequacy of resources, management support, and professional recognition and development opportunities.

\section{Self-employed caseloading midwives are "finding it better"}

A significant finding of this study was that self-employed midwives, providing continuity of care in a caseload model, either full-time or combined with some employed work, had much better emotional health (lower levels of burnout, anxiety, stress and depression) than midwives working in an exclusively employed capacity. This study adds to the body of evidence demonstrating that working in a caseload model, with supportive midwifery partners, work flexibility and autonomy, is potentially protective. For example, Australians Newton, Forster and McLachlan (2011) compared the levels of burnout using the CBI in a group of employed caseloading and employed non-caseloading midwives. Although they tested relatively small numbers, these researchers found significantly less burnout, across all three domains, in the 22 midwives working in a caseload model than in the 130 midwives who worked in the standard fragmented Australian model of maternity care (antenatal care, labour and birth care, postnatal care).

\section{The high number of self-employed midwives working in a caseload model is a unique foundational feature of New Zealand maternity care. The result of our study suggests that this model of care is sustainable but does require careful consideration of professional and family commitments.}

The high number of self-employed midwives working in a caseload model is a unique foundational feature of New Zealand maternity care. The result of our study suggests that this model of care is sustainable but does require careful consideration of professional and family commitments. There is a need to balance the positive benefits of working closely with women against the potential negative issue of longer working hours. In addition to having better emotional health, this study revealed that midwives working in a self-employed capacity also recorded high levels of empowerment. Although the PEMS has not been used widely outside Ireland (where it was developed), which limits direct comparisons, the psychometric properties of our adapted version were supported in this study (Pallant, Dixon, Sidebotham, \& Fenwick, 2016). When the new four-factor structure was applied the results again supported the work of others who have argued that having a sense of autonomy and feeling empowered are protective against burnout in midwives working in a caseload model (Collins 
et al., 2010; Ministry of Health, 2015; Sandall, 1997; Yoshida \& Sandall, 2013).

Perhaps not surprisingly, self-employed midwives, whose main practice environment was the community and/or women's homes, rated the hospital environment more poorly than their employed colleagues. Of particular note was the domain of Doctor/ Midwife Relationships, which elicited midwives' perceptions on relationships, collaboration and team work with doctors. Midwives who worked external to the institution had lower scores in these domains. Globally there has been limited research examining the interface between midwives who work in a self-employed capacity, like the New Zealand midwives in this study, and other health professionals working for organisations such as hospitals. In her study of UK community midwives, Hunter (2010) was perhaps one of the first to suggest that these midwives engaged in higher levels of emotion work (managing their own and others' emotions) when "coming in" to the hospital environment, as a result of a "clash" in philosophies. While caseload midwives were aligned with women, midwives in the hospital system were aligned to the institution, despite being employed by the same overall hospital trust. Canadian researchers, Bourgeault, Sutherns, MacDonald and Luce (2012), have also explored the work environment of community midwives who provided care to women in both home and hospital settings. Similarly to Hunter's findings, the Canadian midwives described feeling like "visitors" when working within the hospital and that they needed to negotiate social relations with the other hospital staff, which included doctors, nurses, midwives and auxiliary staff.

More recently, Australian researchers, Menke, Fenwick, Gamble, Brittain and Creedy (2014) examined the structures and processes that supported positive health outcomes for vulnerable and disadvantaged childbearing women in a publicly funded, caseload model and found that the midwives were often considered "outsiders". The caseload midwives perceived they were not only treated differently to their midwifery colleagues working on the birth suite, but were afforded limited respect and support from doctors, midwifery managers and midwifery team leaders (Menke et al., 2014).

This study has identified a correlation between midwives having sufficient resources to support their work and midwifery burnout. Resource adequacy involved having enough midwives to provide quality care, enough time and opportunity for midwives to spend time with their clients and the ability to discuss client care problems with other midwives.

In the current study the self-employed midwives considered they received more professional recognition from the medical profession than the employed midwives (according to the PES) but rated the Doctor/Midwife Relationships lower. This may be due to the more limited opportunities to develop relationships and teamwork with hospital doctors when the majority of the midwife's work is undertaken within the community environment. It's likely that midwives who had a "foot in both camps" were better off as a result of not only having longitudinal relationships with women but also more opportunities to develop relationships and teamwork with hospital personnel within the employed environment.

\section{Employed midwives "doing it tough"}

Although our results support the emotional benefits afforded to midwives working in caseload models, what becomes evident is that those midwives working in an exclusively employed capacity were significantly worse off. While levels of stress and depression were high but not significantly different between groups, midwives working in an employed model were much more likely to be categorised as having moderate, severe or extreme anxiety and had levels well above the general population norm. This resonates to some degree with Hegney et al. (2014), who found significantly elevated levels of anxiety with regard to nursing, when they explored compassion fatigue in a group of 132 nurses working in an Australian tertiary hospital.

\section{Although our results support the emotional benefits afforded to midwives working in caseload models, what becomes evident is that those midwives working in an exclusively employed capacity were significantly worse off.}

There is limited work exploring anxiety in midwives. The work of Hood, Fenwick and Butt (2010) perhaps provides some insight. In this Australian qualitative study the researchers explored midwives' experiences of an external review of obstetric services. The high level of scrutiny eventually resulted in midwives experiencing significant fear and anxiety around their clinical decision making and practice.

In our study, the exclusively employed midwives also had significantly higher levels of personal and work-related burnout than their self-employed colleagues. The emotional health of these New Zealand midwives was similar to that reported by two studies with smaller cohorts of employed Australian midwives using similar methodology (Jordan, Fenwick, Slavin, Sidebotham, \& Gamble, 2013; Newton, McLachlan, Willis, \& Forster, 2014), where high levels of personal and work-related burnout were reported. Taken together, these three studies demonstrate that those midwives in exclusively employed models felt less empowered when compared to their self-employed/caseloading colleagues, considering themselves to be less skilled, less autonomous and having lower professional standing.

Autonomy has been described as having control over your sphere of activity, having the right and capacity to make and act upon decisions, having this right acknowledged by others and taking responsibility for decisions made (Pollard, 2003). In her study exploring facilitators and barriers to autonomy, Pollard (2003) found that good relationships and lack of hierarchy between midwives facilitated autonomy, with the greatest barrier to autonomy being the power of the medical profession. In New Zealand the partnership model of midwifery care is the foundational philosophy of care for midwives and relies on partnerships formed with women, other midwives and health professionals to enhance empowerment and autonomy. Partnership requires equality of status, responsibility and decision making (Guilliland \& Pairman, 2010). Further work is needed to explore midwifery 
perceptions of facilitators and barriers to autonomy within the hospital environment.

\section{The importance of having sufficient resources}

This study has identified a correlation between midwives having sufficient resources to support their work and midwifery burnout. Resource adequacy involved having enough midwives to provide quality care, enough time and opportunity for midwives to spend time with their clients and the ability to discuss client care problems with other midwives. This issue was also identified by Hildingsson et al. (2013), who explored burnout amongst 475 Swedish midwives and found that a lack of staff and resources, along with a stressful work environment, were factors that contributed to burnout in midwives. When midwives work in busy practice environments where they feel unable to provide quality woman-centred care, there is an increase in stress (Fenwick et al., 2012) which commonly features as a reason midwives seek to leave the profession (Kirkham \& Morgan, 2006; Kirkham et al., 2006; Sullivan, Lock, \& Homer, 2011). The New Zealand Midwifery Employee Representation and Advisory Service (MERAS) has identified a set of midwifery staffing standards for maternity facilities to ensure adequate midwifery staffing levels (MERAS, 2014). The provision of quality maternity services relies on having sufficient midwives within a facility to provide clinical governance and quality care. Further work is needed to determine whether the midwifery staffing standards are being met, with a need to highlight the potential impact on the emotional wellbeing of the midwifery workforce when there are inadequate midwifery personnel. Working conditions can influence mental health, so there is a need to consider what constitutes healthy working conditions and how they can be achieved (Seidler et al., 2014).

\section{The presence of a supportive manager is equally important to employed and self-employed midwives as both need seamless transition through the institutional systems and processes that enable them to provide woman- centred care.}

\section{Midwifery managers can make a difference}

Within the PEMS and PES, midwives assessed communication, levels of support and their perception of being listened to, and valued by, their midwifery manager. Where midwives perceived the quality of the support received from midwifery management to be low, particularly for the employed midwives, there were associated elevated levels of burnout. Again this is consistent with the findings of another study (Ball et al., 2002), where lack of management support has been identified as being one of the key issues contributing to midwives leaving the profession. Certainly the large body of work undertaken with registered nurses demonstrates how fundamental the unit level manager is to nurses' ability to provide quality care, gain social capacity and have job satisfaction; all of which protect against emotional exhaustion (van Bogaert, Kowalski, Weeks, van Heusden, \& Clarke, 2013). The presence of a supportive manager is equally important to employed and self-employed midwives as both need seamless transition through the institutional systems and processes that enable them to provide woman-centred care.

\section{STRENGTHS AND LIMITATIONS}

A strength of this study is the large sample size with good representation of midwives working across New Zealand and in both employed and self-employed capacities. Having said this, we acknowledge that the midwives were recruited using convenience sampling and the questionnaire was self-administered. It is possible that a response bias may be present with only those with strong views responding. In addition, New Zealand's maternity system has a unique model of care with continuity of care supported and promoted for all women through a variety of frameworks and specifically the Maternity Services (Section 88) notice $(\mathrm{MOH}$, 2007). This model of maternity care is different to other countries and results may therefore be context specific and need to be interpreted with caution.

\section{CONCLUSION}

This study explored aspects of emotional wellbeing in a large cohort of midwives working in the New Zealand maternity care context. Despite working more hours, the midwives in our survey who worked across their scope of practice and provided continuity of care (even if also undertaking some employed work), were emotionally better off than their exclusively employed colleagues. Midwives working solely in an employed situation, where maternity care is delivered largely in a fragmented way and where midwives' scope of practice is limited, were found to have significantly higher levels of anxiety and burnout. Employed midwives reported lower levels of autonomy, empowerment and professional recognition, with less access to resources. For all groups, but particularly employed midwives, the quality of midwifery management was fundamental to how midwives assessed their emotional health. While for the New Zealand context there are strong messages about how to better support those in employed models, internationally the results add to the body of knowledge that "debunks" the assumption that providing caseload care is detrimental to midwives and their emotional wellbeing.

\section{ACKNOWLEDGEMENTS AND CONFLICT OF INTEREST DISCLOSURE}

We would like to thank all of the midwives who participated in this study, and the New Zealand College of Midwives and Auckland University of Technology for initiating and funding the New Zealand arm of the WHELM study. The New Zealand authors of this paper are all members of the New Zealand College of Midwives; however, no author received any financial benefit from undertaking the study.

\section{REFERENCES}

Bakker, A. B., Schaufeli, W. B., Sixma, H. J., Bosveld, W., \& van Dierendonck, D. (2000). Patient demands, lack of reciprocity, and burnout: A five-year longitudinal study among general practitioners. Journal of Organizational Behavior, 21(4), 425-441. doi: http://dx.doi. org/10.2307/3100325

Ball, L., Curtis, P., \& Kirkham, M. (2002). Why do midwives leave? Talking to managers. Sheffield, England: University of Sheffield.

Borritz, M., Rugulies, R., Bjorner, J. B., Villadsen, E., Mikkelsen, O. A., $\&$ Kristensen, T. S. (2006). Burnout among employees in human service work: design and baseline findings of the PUMA study. Scandinavian Journal of Public Health, 34(1), 49-58.

Bourgeault, I. L., Sutherns, R., MacDonald, M., \& Luce, J. (2012). Problematising public and private work spaces: Midwives' work in hospitals and in homes. Midwifery, 28(5), 582-590. doi: http://dx.doi. org/10.1016/j.midw.2012.06.002

Cohen, J. (1988). Set correlation and contingency tables. Applied Psychological Measurement, 12(4), 425-434. 
Collins, C. T., Fereday, J., Pincombe, J., Oster, C., \& Turnbull, D (2010). An evaluation of the satisfaction of midwives' working in midwifery group practice. Midwifery, 26(4), 435-441. doi: http://dx.doi. org/10.1016/j.midw.2008.09.004

Deery, R. (2005). An action-research study exploring midwives' support needs and the affect of group clinical supervision. Midwifery, 21(2), 161-176.

Deery, R., \& Kirkham, M. (2006). Supporting midwives to support women. In L. A. Page \& R. McCandlish (Eds.), The New Midwifery Science and Sensitivity in Practice (2nd ed.). Edinburgh, Scotland: Churchill Livingstone.

Donald, H., Smythe, L., \& McAra-Couper, J. (2014). Creating a better work-life balance. New Zealand College of Midwives Journal, 49, 5-10. doi: http://dx.doi.org/10.12784/nzcomjnl49.2014.1.5-10

Fenwick, J., Hammond, A., Raymond, J., Smith, R., Foureur, M., Homer, C., \& Symon, A. (2012). Surviving not thriving: newly qualitfied midwives' transition to practice. Journal of Clinical Nursing, 21, 2054-2063.

Guilliland, K., \& Pairman, S. (2010). The Midwifery Partnership - a model for practice (2nd ed.). Christchurch, New Zealand: New Zealand College of Midwives.

Hegney, D. G., Craigie, M., Hemsworth, D., Osseiran-Moisson, R., Aoun, S., Francis, K., \& Drury, V. (2014). Compassion satisfaction, compassion fatigue, anxiety, depression and stress in registered nurses in Australia: study 1 results. Journal of Nursing Management, 22(4), 506518. doi: http://dx.doi.org/10.1111/jonm.12160

Henry, J., \& Crawford, J. (2005). The short-form version of the Depression Anxiety Stress Scales (DASS-21): construct validity and normative data in a large non-clinical sample. British Journal Clinical Psychology, 44, 227-239.

Hildingsson, I., Westlund, K., \& Wiklund, I. (2013). Burnout in Swedish midwives. Sexual \& Reproductive Healthcare, 4(3), 87-91. doi: http://dx.doi.org/10.1016/j.srhc.2013.07.001

Hood, L., Fenwick, J., \& Butt, J. (2010). A story of scrutiny and fear: Australian midwives' experiences of an external review of obstetric services, being involved with litigation and the impact on clinical practice. Midwifery, 26(3), 268-285.

Hunter, B. (2010). Mapping the emotional terrain of midwifery: What can we see and what lies ahead? International Journal of Work Organisation and Emotion, 3(3), 253-269.

Jordan, K., Fenwick, J., Slavin, V., Sidebotham, M., \& Gamble, J. (2013). Level of burnout in a small population of Australian midwives. Women and Birth, 26(2), 125-132. doi: http://dx.doi.org/10.1016/j. wombi.2013.01.002

Kirkham, M., \& Morgan, R. (2006). Why Midwives return and their subsequent experience. Women's Informed Childbearing and Health Research Group. Sheffield, England: University of Sheffield.

Kirkham, M., Morgan, R., \& Davies, C. (2006). Why do Midwives Stay? Women's Informed Childbearing and Health Research Group. Sheffield, England: University of Sheffield.

Kristensen, T., Borritz, M., Villadsen, E., \& Christensen, K. (2005). The Copenhagen Burnout Inventory: A new tool for the assessment of burnout. Work and Stress, 19(3), 192-207.

Lovibond, S., \& Lovibond, P. (1995). Manual for the Depression Anxiety Stress Scales (2nd ed.). Sydney, Australia: Psychology Foundation of Australia.

Matthews, A., Scott, P., Gallagher, P., \& Corbally, M. (2006). An exploratory study of the conditions important in facilitating the empowerment of midwives. Midwifery, 22, 181-191.

Matthews, A., Scott, P., \& Gallagher, P. (2009). The development and psychometric evaluation of the Perceptions of Empowerment in Midwifery Scale. Midwifery, 25, 327-335.

McAra-Couper, J., Gilkison, A., Crowther, S., Hunter, M., Hotchin, C., \& Gunn, J. (2014). Partnership and reciprocity with women sustain Lead Maternity Carer midwives in practice. New Zealand College of Midwives Journal, 49, 27-31. doi: http://dx.doi.org/10.12784/ nzcomjnl49.2014.5.29-33

McLardy, E. (2003). On-call 24/7 midwives negotiating home and work boundaries. Unpublished Masters' thesis, Victoria University of Wellington.

Menke, J., Fenwick, J., Gamble, J., Brittain, H., \& Creedy, D. (2014). Midwives' perceptions of organisational structures and processes influencing their ability to provide caseload care to socially disadvantaged and vulnerable women. Midwifery, 30(10), 1096-1103. doi: http:// dx.doi.org/10.1016/j.midw.2013.12.01

MERAS. (2014). Midwifery Staffing Standards for Maternity Facilities. Christchurch, New Zealand: Midwifery Employee Representation \& Advisory Service.

Midwifery Council of New Zealand. (2013). 2013 Midwifery Workforce Survey: Midwifery Council of New Zealand.

Ministry of Health. (2007). Primary Maternity Services Notice 2007. New Zealand Gazette, No 41.

Ministry of Health. (2015). Report on Maternity 2012. Wellington, New Zealand: Ministry of Health.

Newton, M., Forster, D., \& McLachlan, H. (2011). Exploring burnout among caseload and non-caseload midwives Journal of Paediatrics and Child Health, 47 (Supplement 1), 98-99.

Newton, M., McLachlan, H., Willis, K., \& Forster, D. (2014). Comparing satisfaction and burnout between caseload and standard care midwives: findings from two cross-sectional surveys conducted in Victoria, Australia. BMC Pregnancy and Childbirth, 14, 426. doi: http:// dx.doi.org/10.1186/s12884-014-0426-7

Nunnally, J. (1978). Psychometric Theory. New York, USA: McGraw-Hill.

Pallant, J. F., Dixon, L., Sidebotham, M., \& Fenwick, J. (2015). Further validation of the perceptions of empowerment in midwifery scale. Midwifery, 31(10), 941-945. doi: http://dx.doi.org/10.1016/j. midw.2015.05.008

Pallant, J. F., Dixon, L., Sidebotham, M., \& Fenwick, J. (2016). Adaptation and psychometric testing of the Practice Environment Scale for use with midwives. Women and Birth, 29(1), 24-29.

Pollard, K. (2003). Searching for autonomy. Midwifery, 19, 113-124.

Roberts, D. L., Cannon, K. J., Wellik, K. E., Wu, Q., \& Budavari, A. I. (2013). Burnout in inpatient-based versus outpatient-based physicians: A systematic review and meta-analysis. Journal of Hospital Medicine, 8(11), 653-664. doi: http://dx.doi.org/10.1002/jhm.2093

Sandall, J. (1997). Midwives' burnout and continuity of care. British Journal of Midwifery, 5(2), 106-111.

Sandall, J. (1998). Occupational burnout in midwives: new ways of working and the relationship between organizational factors and psychological health and wellbeing. Risk Decision and Policy, 3(3), 213-232.

Seidler, A., Thinschmidt, M., Deckert, S., Then, F., Hegewald, J., Nieuwenhuijsen, K., \& Riedel-Heller, S. (2014). The role of psychosocial working conditions on burnout and its core component emotional exhaustion - a systematic review. Journal of Occupational Medicine and Toxicology, 9(1). doi: http://dx.doi.org/10.1186/17456673-9-10

Sullivan, K., Lock, L., \& Homer, C. (2011). Factors that contribute to midwives staying in midwifery: a study in one area health service in New South Wales, Australia. Midwifery, 27(3), 331-335.

Van Bogaert, P., Kowalski, C., Weeks, S., van Heusden, D., \& Clarke, S. (2013). The relationship between nurse practice environment, nurse work characterstics, burnout and job outcome and quality of nursing care: A cross sectional survey. International Journal of Nursing Studies, 50, $1667-1677$.

Wakelin, K., \& Skinner, J. (2007). Staying or leaving: A telephone survey of midwives, exploring the sustainability of practice as Lead Maternity Carers in one urban region of New Zealand. New Zealand College of Midwives Journal, 37, 10-14.

Yoshida, Y., \& Sandall, J. (2013). Occupational burnout and work factors in community and hospital midwives: A survey analysis. Midwifery, 29(8), 921-926. doi: http://dx.doi.org/10.1016/j. midw.2012.11.002

Young, C. (2011). The experience of burnout in case loading midwives. Unpublished Doctoral thesis. Auckland University of Technology. Retrieved from http://aut.researchgateway.ac.nz/handle/10292/2447

\section{Accepted for publication February 2017}

Dixon, L., Guilliland, K., Pallant, J., Sidebotham, M., Fenwick, J., McAra-Couper, J., \& Gilkison, A. (2016). The emotional wellbeing of New Zealand midwives: Comparing responses for midwives in caseloading and shift work settings. New Zealand College of Midwives Journal, 53, $5-14$

http://doi.org/10.12784/nzcomjnl53.2017.1.5-14 